\title{
One step PCR for detection of Staphylococcus aureus specific sequence gene and mecA gene in Northwestern Nigerian hospitals
}

\author{
AS Kumurya \\ From 3rd International Conference on Prevention and Infection Control (ICPIC 2015) \\ Geneva, Switzerland. 16-19 June 2015
}

\section{Introduction}

Methicillin - resistant Staphylococcus aureus (MRSA) has been noted as one of the main pathogen of public health importance. Detection of the mec A gene by polymerase chain reaction (PCR) is the gold standard for identifying methicillin-resistant Staphylococcus aureus.

\section{Objectives}

In order to accelerate the procedure of identification in clinical microbiology laboratories, it is very important to havea simple and rapid method for DNA extraction. In this work, a one step PCR assay for the detection of clinically relevant antibiotic resistance gene (mec A gene) harbored by some Staphylococcus aureus isolates and for the simultaneousidentification of such isolates at the species level has been described.

\section{Methods}

In this work, a rapid method for bacterial DNA extraction directlyfrom a single colony that gave quality DNA for PCR in as littleas 15 minutes was used. PCR was used to amplify both the Staphylococcus aureus specific sequence gene and mec A gene of 100 isolates in Northwestern Nigeria with the amplicon size of 107 and 532 bp respectively. The performance and robustness of the assay was evaluated with a control strain of methicillin susceptible Staphylococcus aureus(MSSA).- ATCC 25923.

\section{Results}

All the isolates $(\mathrm{n}=100)$ expressed Staphylococcus aureus specific sequence gene in their PCR products. Only 5 isolates $(5.0 \%)$ were confirmed as MRSA based on the detection of mec A gene. This protocol yielded good-quality target DNA for PCRamplification. Amplifications using that DNA gave rise to goodquantities of the expected PCR fragments.

\section{Conclusion}

This assay offers a rapid, simple, feasible, specific, sensitive, and accurate identification of MRSA clinical isolates and could be systematically applied as a diagnostic test in clinical microbiology laboratories, facilitating the design and use of antibiotic therapy. Hence, considering that it represents a cost-effective method and helping treatment to be initiated withoutdelay.

\section{Disclosure of interest}

None declared.

Published: 16 June 2015

\section{doi:10.1186/2047-2994-4-S1-P196}

Cite this article as: Kumurya: One step PCR for detection of Staphylococcus aureus specific sequence gene and mecA gene

in Northwestern Nigerian hospitals. Antimicrobial Resistance and Infection Control 2015 4(Suppl 1):P196.

Medical Laboratory Science, Bayero University Kano, Kano, Nigeria 